\title{
Exogenous surfactant therapy for pediatric patients with the acute respiratory distress syndrome
}

\author{
JAMES F LEWIS MD FRCPC, JASVINDER S DHILLON MD FRCPC, RAM N SINGH MD FRCPC, \\ CRAIG C JOHNSON RRT , TIMOTHY C FREWEN MD FRCPC \\ Department of Medicine, St Joseph's Health Centre, The University of Western Ontario, and \\ Paediatric Critical Care Medicine, Children's Hospital of Western Ontario, The University of \\ Western Ontario, London, Ontario; and the Paediatric Intensive Care Unit, Children's Hospital \\ of Eastern Ontario, University of Ottawa, Ottawa, Ontario
}

JF LEWIS, JS DHILlon, RN Singh, CC Johnson, TC FREWEN. Exogenous surfactant therapy for pediatric patients with the acute respiratory distress syndrome. Can Respir J 1997;4(1):21-26.

Exogenous surfactant administration is currently being tested in patients with the acute respiratory distress syndrome (ARDS). The results of the studies have varied because several factors may influence the host's response to this therapy. This clinical pilot study was designed to evaluate the safety and efficacy of exogenous surfactant administration in pediatric patients with ARDS. Surfactant was administered to 13 patients with severe lung dysfunction, and eight of these patients experienced a significant improvement in oxygenation after the first dose of surfactant. In these patients the exogenous surfactant was administered within $48 \mathrm{~h}$ of the diagnosis of ARDS, whereas in the five patients who did not respond, surfactant was administered several days after the onset of ARDS. Responders also spent fewer days on a mechanical ventilator and less time in intensive care compared with nonresponders. Based on the results of this pilot study, a more appropriate multicentre clinical trial should be designed to evaluate this treatment strategy.

Key Words: Acute respiratory distress syndrome (ARDS), Respiratory failure, Surfactant
Thérapie par surfactant exogène chez les patients pédiatriques atteints du syndrome de détresse respiratoire aiguë

RÉSUMÉ : L'administration de surfactant exogène pour traiter les patients atteints du syndrome de détresse respiratoire aiguë (SDRA) est actuellement à l'étude. Les résultats des études varient du fait que plusieurs facteurs peuvent influencer la réponse de l'hôte à cette thérapie. La présente étude clinique pilote a été conçue pour évaluer la sûreté et l'efficacité de l'administration de surfactant exogène chez les patients pédiatriques souffrant du SDRA. On a administré du surfactant à 13 patients accusant une dysfonction pulmonaire grave, et 8 de ces patients ont pu améliorer leur oxygénation de façon significative après avoir reçu la première dose de surfactant. Chez ces patients, le surfactant avait été administré dans les 48 heures suivant le diagnostic de SDRA, tandis que chez les 5 patients qui n'ont pas répondu au traitement, le surfactant avait été administré plusieurs jours après le déclenchement du SDRA. Les patients qui ont répondu au traitement ont passé moins de jours sous ventilation mécanique et moins de temps aux soins intensifs que les patients n'ayant pas répondu à la thérapie. D'après les résultats de cette étude pilote, on devrait mener un essai clinique multicentrique plus approprié pour évaluer cette stratégie thérapeutique.

Correspondence and reprints: Dr James F Lewis, Department of Respirology, St Joseph's Health Centre, 268 Grosvenor Street, London, Ontario N6A 4V2. Telephone 519-646-6288, fax 519-646-6064, e-mail jflewis@julian.uwo.ca 
A cute respiratory distress syndrome (ARDS) in pediatric patients is associated with a high mortality, despite advances in tertiary critical care support and an improved understanding of disease pathophysiology (1-3). Although the etiology and clinical presentation of neonates with the infant respiratory distress syndrome (RDS) and older children with ARDS differs, both conditions are associated with either primary surfactant deficiency or secondary alterations of the surfactant system (4-7). In both clinical settings, surfactant abnormalities result in lung dysfunction that manifests as hypoxemia and decreased pulmonary compliance. Successful treatment of neonatal RDS with exogenous surfactant (4) has prompted some investigators to suggest that this therapy may also benefit patients with ARDS $(4,5,7)$.

Studies examining both bronchoalveolar lavage isolated from patients with ARDS (6-9) and alveolar lavage samples obtained from animals with acute lung injury (10-12) have demonstrated altered biochemical composition and functional abnormalities of the recovered surfactant. Together these findings indicate that surfactant alterations contribute to the lung dysfunction associated with ARDS and support the hypothesis that exogenous surfactant may improve lung function in these patients.

Clinical experience with exogenous surfactant replacement as a treatment modality for ARDS is limited. Most case studies have reported efficacy in severely ill patients, and these data suggest that improvement in oxygenation and pulmonary compliance are possible following surfactant administration (13-18). Two recent multicentre clinical trials evaluating exogenous surfactant treatment for adults with established ARDS have yielded conflicting results. In one study, aerosolization of a synthetic surfactant resulted in no improvement in either oxygenation or pulmonary compliance, nor in 28-day mortality (17). A second study showed that instillation of a modified natural bovine surfactant led to both short term benefits in oxygenation and a significant reduction in mortality (16).

Experience using exogenous surfactant administered to pediatric patients with ARDS is even more limited. Bohn and colleagues (15) reported that exogenous surfactant instilled into the lungs of eight children with severe respiratory failure due to ARDS resulted in immediate improvements in oxygenation. Despite these promising results, animal studies suggest that earlier administration of exogenous surfactant over the course of the injury may result in superior outcomes $(7,19,20)$. To date, there are few clinical data to support this hypothesis, and clinical trials are currently designed to administer the surfactant at relatively late stages of the patient's disease $(16,17)$. Because of the limited data available evaluating this therapy in pediatric patients, an uncontrolled pilot study in 13 pediatric patients with ARDS was conducted to assess the safety and physiological efficacy of surfactant administration in this patient population. The goals were to develop experience with this treatment modality in this patient population and gain insight from the results so that larger, controlled clinical trials could be more appropriately designed.

\section{PATIENTS AND METHODS}

This clinical pilot study was conducted at two Canadian pediatric intensive care units using the same protocol approved by each university's Institutional Review Boards. The children received treatment with bovine lipid extract surfactant (bLES) (BLES Biochemicals) after informed parental consent was obtained.

Study design: This study was a pilot investigation evaluating the safety and efficacy of exogenous surfactant administration in pediatric patients with severe ARDS. Patients were entered into the study if they had a clinical history and chest radiograph compatible with the diagnosis of ARDS (2,3). They were required to meet the following inclusion criteria: age between two weeks and 16 years; acute respiratory failure necessitating assisted positive pressure ventilation: $\mathrm{PaO}_{2}$ :fraction of inspired oxygen $\left(\mathrm{FiO}_{2}\right)$ ratio less than 150 and positive end-expiratory pressure (PEEP) $6 \mathrm{~cm} \mathrm{H}_{2} \mathrm{O}$ or greater. Patients were excluded from the study if they had evidence of cardiogenic pulmonary edema as demonstrated by a pulmonary capillary wedge pressure $18 \mathrm{mmHg}$ or greater, or clinical features of congestive cardiac failure, such as gallop rhythm, hepatomegaly, etc. Patients with significant asymmetric chronic lung disease or evidence of congenital lobar emphysema were also excluded.

All eligible patients were treated with an initial dose of exogenous surfactant during continuous monitoring of arterial blood pressure and oxygen saturation by pulse oximetry. In addition all patients underwent pulmonary artery catheterization to measure the pulmonary artery pressure. Data collected on these patients included hemodynamic monitoring, ventilation parameters, oxygen saturation monitoring and arterial blood gases.

The recorded hemodynamic parameters included systolic arterial pressure (SAP), systolic mean arterial pressure (SMAP), systolic pulmonary arterial pressure (PAP) and mean pulmonary artery pressure (PMAP). In addition to the above monitoring these patients underwent cardiac output (CO) measurements in duplicate using the thermodilution technique with an injectate volume of $5 \mathrm{~mL}$ normal saline at an injectate temperature of 0 to $5^{\circ} \mathrm{C}$. The cardiac index $(\mathrm{CI})$ was calculated as $\mathrm{CI}=\mathrm{CO} /$ body surface area. The ventilation parameters recorded included respiratory peak inspiratory pressure (PIP), mean airway pressure (Paw) and PEEP as well as the $\mathrm{FiO}_{2}$. These data were obtained before surfactant administration and at 15 min intervals after surfactant instillation for the first hour. Subsequent measurements were obtained at hourly intervals up to $6 \mathrm{~h}$ after surfactant instillation. Of note, all patients included in this study were ventilated in a relatively similar manner and according to the accepted standard of care in these institutions. During the study no specific mode of ventilation had been proven superior to another in large multicentre clinical trials, so no particular ventilation settings for this study were specified. As a result, the ventilation parameters varied somewhat between both patients and at times within patients. The goal of all ventilation strategies was to optimize oxygenation and $\mathrm{PaCO} 2$ values both before and after surfactant administra- 
TABLE 1

Patient characteristics of 13 patients with acute resipratory distress syndrome before exogenous surfactant administration

\begin{tabular}{|c|c|c|c|c|c|}
\hline Patient & Age & Diagnosis & $\mathrm{PaO}_{2}: \mathrm{FiO}_{2}$ & PIP & PEEP \\
\hline 1 & 3 weeks & Aspiration & 62 & 42 & 12 \\
\hline 2 & 7 months & Liver failure/sepsis & 47 & 32 & 10 \\
\hline 3 & 13 months & Aspiration & 29 & 44 & 10 \\
\hline 4 & 4 months & Bronchiolitis/immunodeficiency & 73 & 34 & 8 \\
\hline 5 & 30 months & Congenital heart disease, pneumonia & 16 & 28 & 7 \\
\hline 6 & 16 years & Burns, sepsis & 74 & 48 & 12 \\
\hline 7 & 8 years & Neuroblastoma & 80 & 44 & 7 \\
\hline 8 & 10 years & Brain tumour, pneumonia & 120 & 52 & 8 \\
\hline 9 & 13 years & Pneumonia/sepsis & 67 & 43 & 8 \\
\hline 10 & 11 months & Aspiration & 77 & 29 & 8 \\
\hline 11 & 6 months & Respiratory syncytial virus, sepsis & 57 & 45 & 6 \\
\hline 12 & 10 months & Congenital heart disease, pneumonia & 70 & 36 & 9 \\
\hline 13 & 2 years & Aspiration & 81 & 52 & 10 \\
\hline
\end{tabular}

$\mathrm{FiO}_{2}$ Fraction of inspired oxygen; PEEP Positive end-expiratory pressure; PIP Peak inspiratory pressure

tion, and to minimize ventilatory changes immediately before and after surfactant therapy so that this variable had minimal effect on acute clinical responses.

The total number of doses of bLES administered was also reported, as were the duration of assisted ventilation and intensive care stay in days before and after bLES administration. In addition to patient outcome, ie, survival or death, the incidence of respiratory complications, such as endotracheal tube obstruction, pulmonary hemorrhage or pneumothorax, was also documented.

Surfactant administration: bLES was used to treat patients enrolled in this study. This preparation is a natural bovine lung lavage extract and has been used extensively for treatment of neonatal RDS in Canada. Patients received a dose of $100 \mathrm{mg} / \mathrm{kg}(4 \mathrm{~mL} / \mathrm{kg})$ intratracheally using the following technique. A syringe with a treatment dose of surfactant was connected to the endotracheal tube via a luer lock connector and surfactant was instilled in three separate aliquots while the head of the bed was maintained at a $45^{\circ}$ elevation. The first aliquot of the dose was instilled in the midline position over 5 to 10 mins during the inspiratory cycle of the ventilator. The second and third aliquots of each dose were instilled in a similar manner with the patient in the left and right lateral positions respectively. The patient was returned to the supine position after the surfactant was administered. A beneficial response was arbitrarily predetermined to be an increase in the $\mathrm{PaO}_{2}: \mathrm{FiO}_{2}$ ratio of at least $20 \%$ from the pretreatment value in response to the first dose of bLES. Subsequent doses of bLES were administered only if a beneficial response to the first dose of bLES occurred.

Statistical analysis: Statistical analysis was performed using ANOVA for SAP, SMAP, PAP, PMAP, PIP, Paw, CI, $\mathrm{PaO}_{2}: \mathrm{FiO}_{2}$ ratio and $\mathrm{PaCO}_{2}$ values reported for each patient before the first dose of bLES compared with their values post-bLES administration at the above time intervals. These values for individual patients who received subsequent doses of surfactant were also compared with their immediate pre-

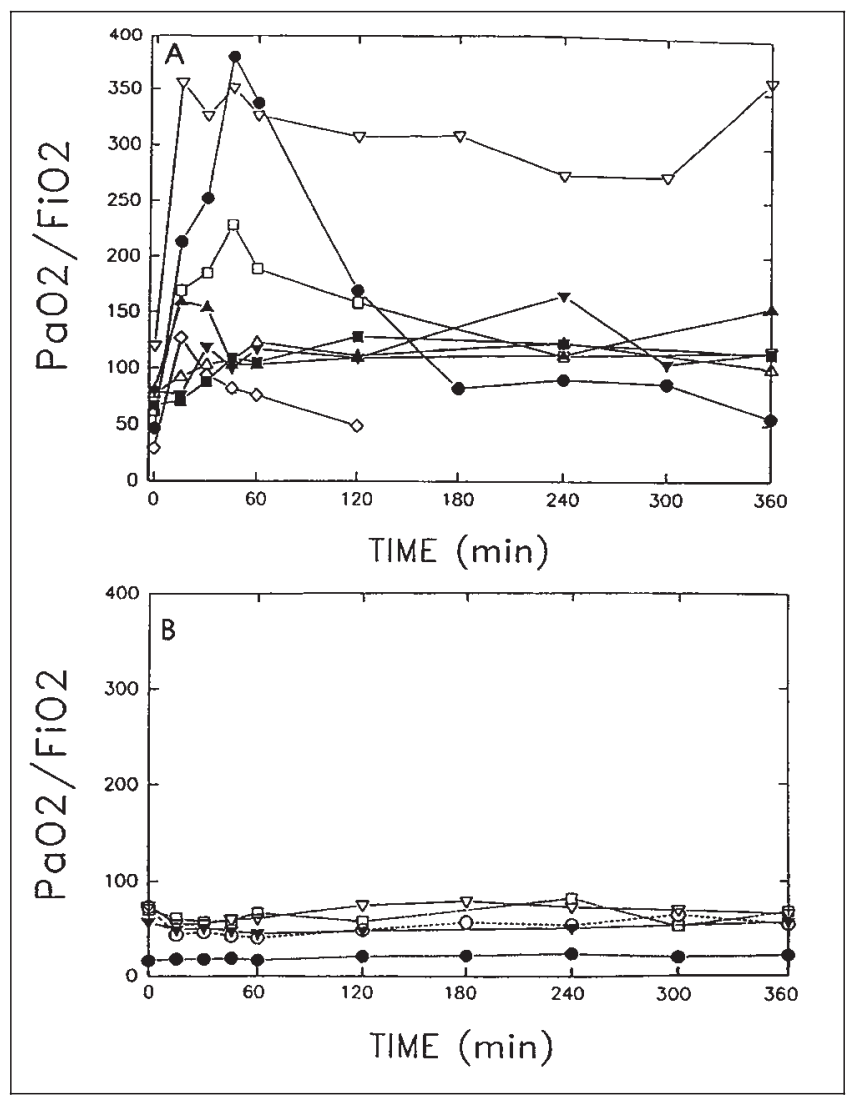

Figure 1) Individual $\mathrm{PaO}_{2}: \mathrm{FiO}_{2}$ values over time for patients that responded to exogenous surfactant (A top) and patients that did not respond to surfactant (B bottom). A Patient $1 \square$; Patient 2 ; Patient $3 \triangleleft$; Patient $7 \nabla$; Patient $8 \nabla$; Patient $9 \mathbf{\square}$; Patient $10 \mathbf{\Delta}$; Patient 13 А. B Patient $4 \bigcirc$; Patient 5 O; Patient 6 V; Patient 11 $\nabla$; Patient $12 \square$

treatment values using ANOVA. A statistically significant difference in the pre- and postsurfactant values was considered present when $\mathrm{P}<0.05$. 


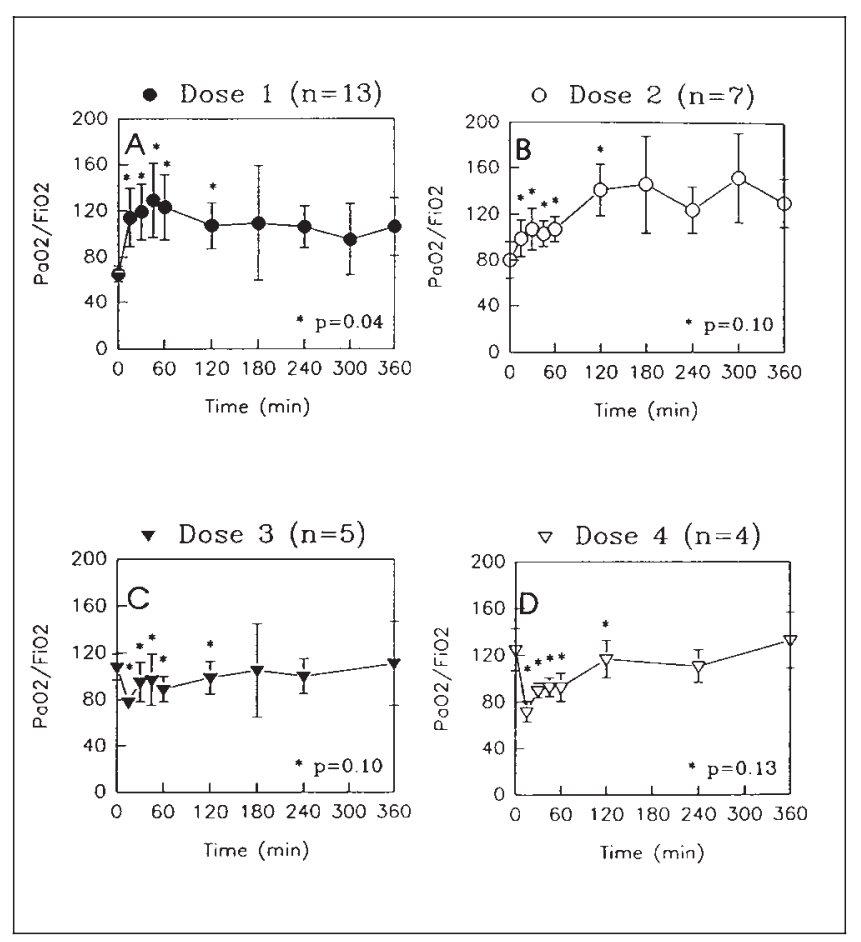

Figure 2) Mean \pm SEM $\mathrm{PaO}$ :Fraction of inspired oxygen ( $\left.\mathrm{FiO}_{2}\right)$ values after each dose of exogenous surfactant administered to patients with acute respiratory distress syndrome. There were significant improvements in $\mathrm{PaO}_{2}: \mathrm{FiO}_{2}$ only in response to the first dose of bovine lipid extract surfactant

\section{RESULTS}

Patient characteristics before treatment: A total of 13 patients were enrolled in this pilot study (Table 1). Ages ranged from three weeks to 16 years with a mean age of four years and four months. All of these children had severe respiratory failure before surfactant administration as indicated by $\mathrm{FiO}_{2}$ requirements exceeding 0.6 , with a mean $\mathrm{PaO}_{2}: \mathrm{FiO}_{2}$ value of $65 \pm 7$, a mean PIP value of $40 \pm 2 \mathrm{~cm} \mathrm{H}_{2} \mathrm{O}$ and a mean PEEP value of $8 \pm 1 \mathrm{~cm} \mathrm{H}_{2} \mathrm{O}$.

Response to treatment: Eight of the 13 patients treated with exogenous surfactant demonstrated a significant improvement in the $\mathrm{PaO}_{2}: \mathrm{FiO}_{2}$ ratio following the first dose of instilled bLES (responders) (Figure 1A). In five of the 13 patients (Figure 1B) there were no improvements whatsoever in the $\mathrm{PaO}_{2}: \mathrm{FiO}_{2}$ values (nonresponders). The two groups of patients were separated retrospectively according to their oxygenation response to bLES. Patient 5 did not exhibit an increase in $\mathrm{PaO}_{2}: \mathrm{FiO}_{2}$ in response to surfactant but had a decrease in PIP and $\mathrm{PaCO}_{2}$ values reflecting an isolated ventilatory response (data not shown). Lack of improvement in oxygenation in this patient may have been caused by the presence of a persistent intracardiac shunt from a patent foramen ovale due to the presence of a pre-existing cyanotic congenital heart disease confirmed postmortem.

Among the 13 patients who received at least one dose of bLES, four patients received three subsequent doses, two patients received one more dose, and one patient received

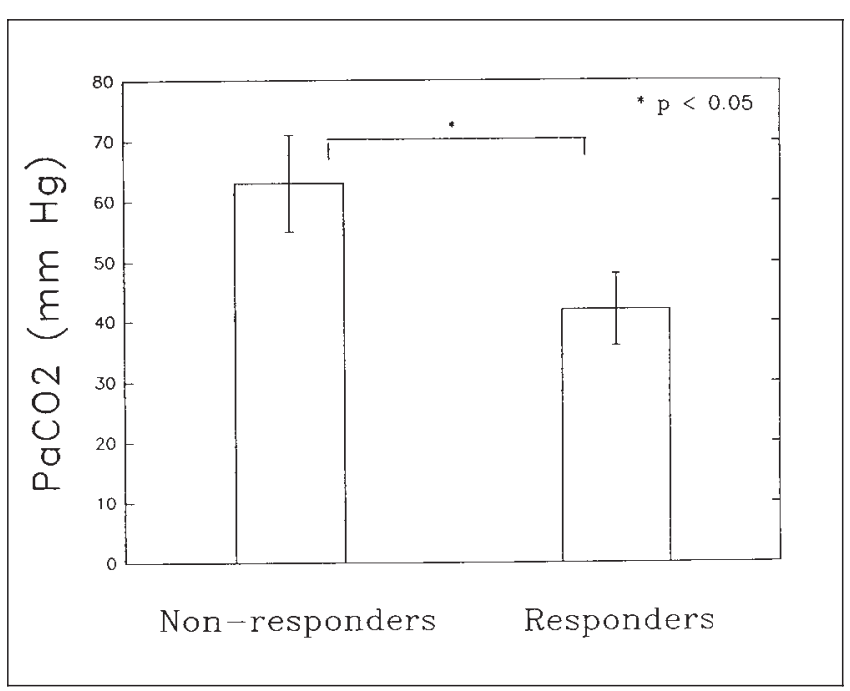

Figure 3) Mean \pm SEM $\mathrm{PaCO}$ values before surfactant administration in patients that eventually responded to exogenous surfactant (increased $\mathrm{PaO}$ :Fraction of inspired oxygen values) compared with patients who did not respond to the surfactant

two subsequent doses. The oxygenation response to all doses of exogenous surfactant for all patients is shown in Figure 2. In response to the first dose of bLES the mean $\mathrm{PaO}_{2}: \mathrm{FiO}_{2}$ ratio improved from a baseline value of $65 \pm 7$ to $114 \pm 25$ over 15 mins with a peak value of $129 \pm 32$ occurring 45 mins after bLES instillation (Figure 2A). There was subsequently a decline in the $\mathrm{PaO}_{2}: \mathrm{FiO}_{2}$ ratio to $107 \pm 20$ by $2 \mathrm{~h}$ post-treatment. Statistically significant improvements in $\mathrm{PaO}_{2}: \mathrm{FiO}_{2}$ values were noted only after the first dose of bLES, and values remained significantly higher than pretreatment values for up $2 \mathrm{~h}$ post-bLES administration. In response to the second dose of bLES, the mean $\mathrm{PaO}_{2}: \mathrm{FiO}_{2}$ ratio improved from a baseline value of $80 \pm 16$ to $107 \pm 18$ at 30 mins, and increased further to $141 \pm 22$ by $2 \mathrm{~h}$ post-treatment (Figure $2 \mathrm{~B})$. The peak value of $152 \pm 39$ occurred at $5 \mathrm{~h}$ post-treatment with a decline to $130 \pm 21$ at $6 \mathrm{~h}$. The third and the fourth doses of bLES failed to show any significant improvements in the $\mathrm{PaO}_{2}: \mathrm{FiO}_{2}$ ratio compared with pretreatment values (Figure 2C,2D).

Mean $\mathrm{PaCO}_{2}$ values showed no significant changes in response to any of the individual doses of bLES. Interestingly, the mean pretreatment $\mathrm{PaCO}_{2}$ values before receiving the first dose of bLES in the eight patients who had significant improvements in oxygenation in response to bLES $(42 \pm 6 \mathrm{mmHg})$ were significantly lower than the pretreatment $\mathrm{PaCO}_{2}$ values in nonresponders $(63 \pm 8 \mathrm{mmHg})$ (Figure 3).

A detailed analysis of data collected from patients given exogenous bLES demonstrated that there were no significant changes in ventilatory parameters after treatment (PIP, PEEP and Paw) or in hemodynamic parameters (SAP, SMAP, PAP, PMAP and CI) after bLES administration compared with their respective pretreatment values.

In all patients, surfactant instillation was tolerated without complications, such as endotracheal tube obstruction, pulmo- 
nary hemorrhage or pneumothorax, during and to $6 \mathrm{~h}$ following surfactant administration.

The final outcome of all 13 patients treated with exogenous surfactant is shown in Table 2. Seven of the 13 patients treated with surfactant died. Three of the deaths occurred in the group of eight patients who showed improvement in $\mathrm{PaO}_{2}: \mathrm{FiO}_{2}$ values in response to the first dose of bLES. In these three patients, mortality was attributed to brain death in patient 7, fulminant liver failure in patient 2 and multisystem organ dysfunction (MSOD) in patient 13. On the other hand, four of the five patients who did not respond to bLES died. In these patients mortality was due to cardiac dysfunction and MSOD in patient 5 and MSOD with severe respiratory failure in patients 4, 6 and 12 .

Mean length of stay in the pediatric intensive care unit was $10 \pm 2$ days for the eight patients who responded to the first dose of bLES and $22 \pm 6$ days for the five patients who did not respond. Similarly, responders spent a mean of $7.5 \pm 1.8$ days on a mechanical ventilator while nonresponders spent $20 \pm 6$ days on a ventilator. Interestingly, the responders received bLES within $24 \mathrm{~h}$ of the initial diagnosis of ARDS whereas four of the five nonresponders received bLES at least six days after diagnosis of ARDS (Table 2). Only a single nonresponder (patient 5 - a patient with ARDS following postoperative cardiac shunt surgery for cyanotic congenital heart disease) received surfactant within $48 \mathrm{~h}$ of the diagnosis of ARDS. In this patient ventilatory parameters improved despite no significant change in $\mathrm{PaO}_{2}: \mathrm{FiO}_{2}$ values as noted previously.

\section{DISCUSSION}

Studies involving animal models of acute lung injury (10-12,18-20) and assays performed on lavage samples obtained from patients with ARDS $(6,8,9)$ suggest that alterations of the endogenous surfactant system contribute, in part, to the lung dysfunction associated with ARDS. Although the limited clinical experience using exogenous surfactant in patients with ARDS is encouraging, recent multicentre clinical trials have reported variable results $(16,17)$. Further understanding of the potential factors that may influence an individual's response to exogenous surfactant will lead to more optimal design of multicentre clinical trials that will evaluate both physiological response to the exogenous surfactant and overall mortality. The data suggest that in future clinical trials exogenous surfactant should be administered relatively early after the injury and that there may be a limit to the number of doses of surfactant required.

It was clear from this study that patients given exogenous surfactant fell into two relatively distinct groups. Patients referred to as responders had at least a $20 \%$ increase in $\mathrm{PaO}_{2}: \mathrm{FiO}_{2}$ after the first dose of surfactant, whereas nonresponders demonstrated no changes in oxygenation. Comparison of patient characteristics in these two groups before surfactant treatment revealed no obvious differences in the etiology of ARDS, age of onset of disease or degree of hypoxemia at the time of treatment. Although the recorded airway pressures of both patient groups were similar before treatment, the $\mathrm{PaCO}_{2}$ values of responders were significantly
TABLE 2

Individual patient responses

\begin{tabular}{lcc}
\hline & Responders & Nonresponders \\
\hline Number of patients & 8 & 5 \\
Total PICU days $( \pm$ SEM) & $10 \pm 2$ & $22 \pm 6$ \\
Total days of ventilation $( \pm$ SEM) & $7.5 \pm 1.8$ & $20 \pm 6$ \\
$\begin{array}{l}\text { Days of ventilation pretreatment } \\
\quad( \pm \text { SEM) }\end{array}$ & $1.0 \pm 0$ & $7.6 \pm 2.1$ \\
Outcome (mortality) & $3 / 8$ & $4 / 5$ \\
\hline
\end{tabular}

PICU Pediatric intensive care unit

lower than those of nonresponders. This observation was made retrospectively and suggests that patients with very poor ventilation efficiencies before treatment may not respond as well to exogenous surfactant. However, because we did not formally measure tidal volumes and did not specify the particular modes of ventilation used in this study (ie, respiratory rates, inspiratory times, etc), we cannot conclude that ventilation efficiency predicts response to exogenous surfactant in patients with ARDS. On the other hand, until data are available demonstrating that a specific mode of ventilation in these patients significantly decreases mortality, it is likely that surfactant will continue to be administered to patients undergoing various ventilation strategies before treatment.

It is possible that the nonresponders had more severe lung injury before treatment compared with the responders, despite similar oxygenation values in the two groups. This is supported by our subsequent finding that nonresponders had been ventilated for a significantly longer period of time after the diagnosis of ARDS was made (at least six days with mechanical ventilation before bLES administration) compared with the responder group. In fact, all eight patients who responded received bLES within 24 to $36 \mathrm{~h}$ of the diagnosis of ARDS. This finding suggests that future controlled clinical trials may result in more optimal outcomes if exogenous surfactant is administered earlier in the course of the disease. Indeed, the timing of surfactant administration in acute lung injury has been shown to be an important factor influencing the response to exogenous surfactant in patients with neonatal RDS (4) and in animal models of hyperoxia exposure $(7,20)$ and repetitive saline lung lavage $(18,19)$. Our study supports the conclusion that the timing of surfactant treatment more accurately predicts a patient's response to this therapy rather than the oxygenation status of the patient.

Another interesting observation was that no further improvements in oxygenation were observed after the second dose of surfactant was administered to responders. Gregory and colleagues (16) found that four doses of instilled surfactant resulted in a superior response in adults with ARDS compared with a similar group of patients who received eight doses. Further studies are required to determine optimal dosing intervals in such patients to make this therapeutic strategy more cost effective. For example, it is possible in our study that patients not responding to the first dose of exogenous surfactant may have responded to subsequent doses, had they 
been administered. Although review of the literature reporting clinical experiences with this treatment modality does not support this hypothesis, it is possible that in some ARDSpatients multiple doses may be necessary.

A final observation from this study was that exogenously instilled bLES was tolerated by all patients, with no evidence of endotracheal tube obstruction or other complications despite the relatively large volumes of surfactant delivered to these patients compared with volumes used in the neonatal population. It is also interesting that despite the severity of respiratory failure in these patients, none of the responders to bLES died of respiratory failure, whereas three of the five nonresponders had severe respiratory insufficiency at death. Respiratory failure in these nonresponders was not related to surfactant instillation because the surfactant instillation had been well tolerated acutely and these deaths occurred several days later. One could conclude from these observations that

ACKNOWLEDGEMENTS: We acknowledge BLES Biochemicals Inc, Abbott Canada Inc and the Physician Service Incorporated for their financial contributions.

\section{REFERENCES}

1. Timmons OD, Dean JM, Vernon DD. Mortality and prognostic variables in children with adult respiratory distress syndrome. J Pediatr 1991;119:896-9.

2. Pfenninger J, Gerber A, Tscjaller J, Zimmerman A. Adult respiratory distress syndrome in children. J Pediatr 1982;101:352-7.

3. Royall JA, Levin DL. Adult respiratory distress syndrome in paediatric patients. I. Clinical aspects, pathophysiology, pathology, and mechanisms of lung injury. J Pediatr 1988;112:169-80.

4. Jobe A, Ikegami M. Surfactant for the treatment of respiratory distress syndrome. Am Rev Respir Dis 1987;136:1256-75.

5. Petty TL, Silvers GW, Paul GW, Stanford RE. Abnormalities in lung elastic properties and surfactant function in adult respiratory distress syndrome. Chest 1979;75:571-4.

6. Hallman M, Spragg R, Harrell JH, Moser KF, Gluck L. Evidence of lung surfactant abnormality in respiratory failure. Study of bronchoalveolar lavage phospholipids, surface activity, phospholipase activity, and plasma myoinositol. J Clin Invest 1982;70:673-83.

7. Lewis JF, Jobe AH. Surfactant and the adult respiratory distress syndrome. Am Rev Respir Dis 1993;147:218-33.

8. Pison U, Seeger W, Buchhorn R, et al. Surfactant abnormalities in patients with respiratory failure after multiple trauma. Am Rev Respir Dis 1989;140:1033-9.

9. Gregory TJ, Longmore WJ, Moxley MA, et al. Surfactant chemical composition and biophysical activity in acute respiratory distress syndrome. J Clin Invest 1991;88:1976-81.

10. Lewis JF, Ikegami M, Jobe AH. Altered surfactant function and metabolism in rabbits with acute lung injury. J Appl Physiol 1990;69:2303-10. this particular treatment strategy was safe in this critically ill patient population, although because this was not a controlled trial, conclusions about the effects of exogenous surfactant on long term outcomes cannot be made.

In summary, we found that instilled exogenous surfactant could be given safely to critically ill pediatric patients with severe ARDS. Optimal responses in oxygenation were obtained when the surfactant was given within 24 to $48 \mathrm{~h}$ of the diagnosis of ARDS. Patients who responded to the exogenous surfactant had no further improvements in gas exchange after the second dose and spent less time on a mechanical ventilator and fewer days in the intensive care unit compared with patients who did not respond to the first dose of surfactant. We believe that an appropriately designed, prospective, randomized, multicentre clinical trial evaluating exogenous surfactant in pediatric patients with ARDS is warranted.

11. Gross NJ, Smith DM. Impaired surfactant phospholipid metabolism in hyperoxic mouse lungs. J Appl Physiol 1981;51:1198-203.

12. Matalon S, Holm BA, Loewen GM, Baker RR, Notter RH. Sublethal hyperoxic injury to the alveolar epithelium and the pulmonary surfactant system. Exp Lung Res 1988;14(Suppl):1021-33.

13. Lachmann B. The role of pulmonary surfactant in the pathogenesis and therapy of ARDS. In: Vincent JL, ed. Update in Intensive Care and Emergency Medicine. Berlin: Springer, 1987:123-4.

14. Nosaka S, Sakai T, Yonekura M, Yoshikawa K. Surfactant for adults with respiratory failure. Lancet 1990;336:947-8.

15. Bohn D, Schindler M, Dagan O, Cox P, Barker G. The use of surfactant replacement therapy and high frequency oscillatory ventilation for the treatment of ventilation induced lung injury in the newborn. Paediatric Critical Care Colloquium, Snowbird, Utah, June 1992.

16. Gregory TJ, Gadek J, Weiland JE, et al. Survanta supplementation in patients with ARDS. Am J Respir Crit Care Med 1994;149:A567. (Abst)

17. Anzueto A, Baughman R, Guntupalli K, et al. An international randomized placebo-controlled trial evaluating the safety and efficacy of aerosolized surfactant in patients with sepsis induced ARDS. N Engl J Med 1996;334:1417-1421.

18. Lachmann B. Surfactant replacement in acute respiratory failure: Animal studies and first clinical trials. In: Lachmann B, ed. Surfactant Replacement Therapy in Neonatal and Adult RDS. New York: Springer-Verlag, 1987:204-11.

19. Berggren P, Lachmann B, Curstedt T, Grossman G, Robertson B. Gas exchange and lung morphology after surfactant replacement in experimental adult respiratory distress syndrome induced by repeated lung lavage. Acta Anaesthesiol Scand 1986;30:321-8.

20. Engstrom PC, Holm BA, Matalon S. Surfactant replacement attenuates the increase in alveolar permeability in hyperoxia. J Appl Physiol 1989;67:688-93. 


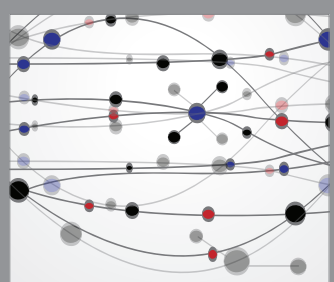

The Scientific World Journal
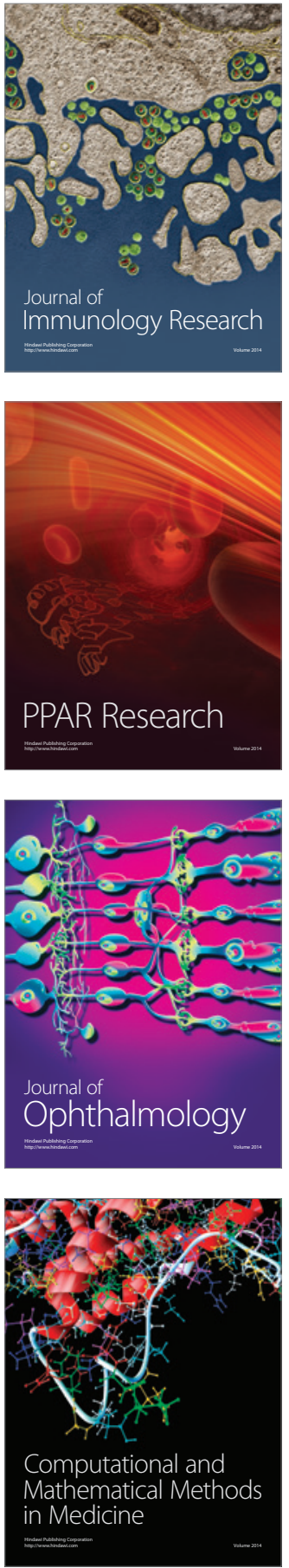

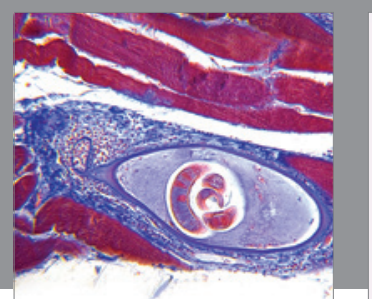

Gastroenterology Research and Practice

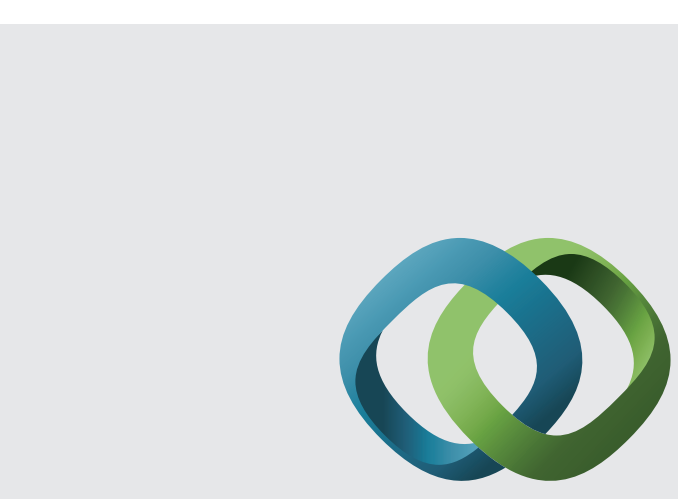

\section{Hindawi}

Submit your manuscripts at

http://www.hindawi.com
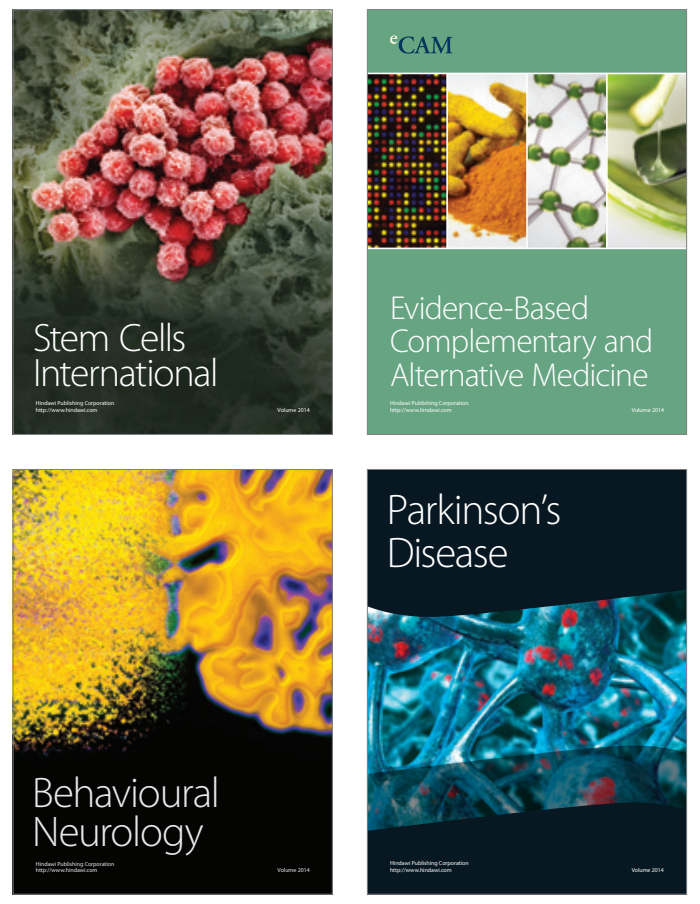
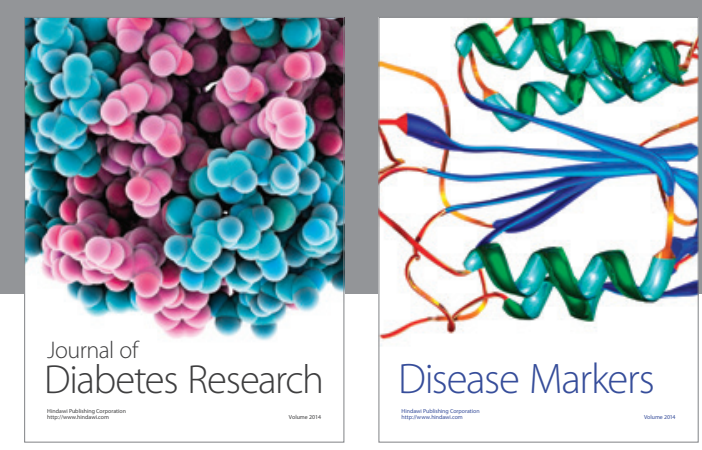

Disease Markers
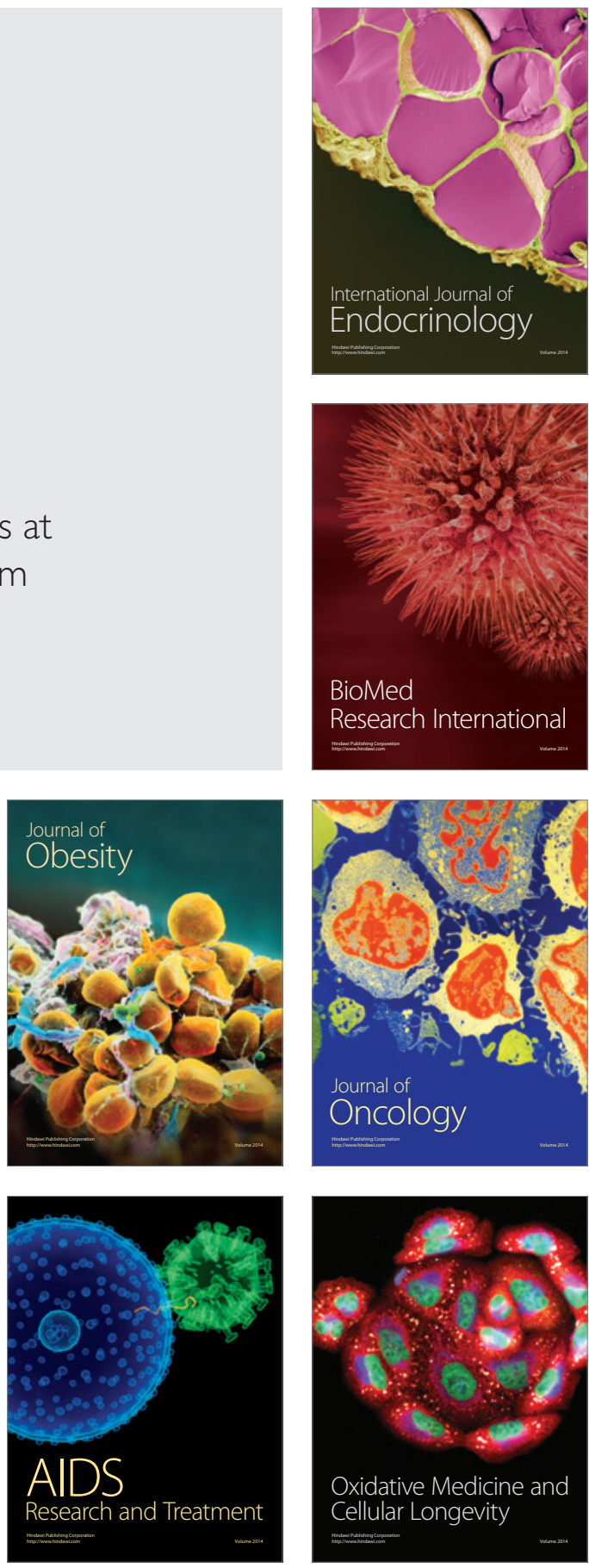